Article

\title{
Investigation on the Mechanical Properties of a Cement-Based Material Containing Carbon Nanotube under Drying and Freeze-Thaw Conditions
}

\author{
Wei-Wen Li ${ }^{1}$, Wei-Ming Ji ${ }^{1}$, Yao-Cheng Wang ${ }^{1, *}$, Yi Liu ${ }^{1}$, Ruo-Xu Shen ${ }^{2}$ and Feng Xing ${ }^{1}$ \\ Received: 8 October 2015; Accepted: 30 November 2015; Published: 14 December 2015 \\ Academic Editor: Geminiano Mancusi \\ 1 Guangdong Key Provincial Durability Center for Marine Structure, \\ Shenzhen Durability Center for Civil Engineering, Department of Civil Engineering, Shenzhen University, \\ Shenzhen 518060, China; liweiwen@szu.edu.cn (W.-W.L.); weimingji163@gmail.com (W.-M.J.); \\ 2141150214@email.szu.edu.cn (Y.L.); xingf@szu.edu.cn (F.X.) \\ 2 Shenzhen Graduate School of Harbin Institute of Technology, Shenzhen 518055, China; \\ ruoxushen@gmail.com \\ * Correspondence: wangyc_szu@126.com; Tel.: +86-755-2691-8013
}

\begin{abstract}
This paper aimed to explore the mechanical properties of a cement-based material with carbon nanotube (CNT) under drying and freeze-thaw environments. Mercury Intrusion Porosimetry and Scanning Electron Microscopy were used to analyze the pore structure and microstructure of CNT/cement composite, respectively. The experimental results showed that multi-walled CNT (MWCNT) could improve to different degrees the mechanical properties (compressive and flexural strengths) and physical performances (shrinkage and water loss) of cement-based materials under drying and freeze-thaw conditions. This paper also demonstrated that MWCNT could interconnect hydration products to enhance the performance of anti-microcracks for cement-based materials, as well as the density of materials due to CNT's filling action.
\end{abstract}

Keywords: carbon nanotube (CNT); cement-based material; mechanical property; durability; drying; freeze-thaw

\section{Introduction}

Carbon nanotube (CNT) is a novel and nano-sized fiber with outstanding mechanical and physical properties. Theoretically, Young's modulus, tensile strength and fracture strain of an individual CNT fiber can reach $1 \mathrm{TPa}, 100 \mathrm{GPa}$ and $15 \%$, respectively [1,2]. Also, CNT has a high specific surface area with a value of up to $1000 \mathrm{~m}^{2} \cdot \mathrm{g}^{-1}$ [3]. Due to these excellent mechanical and physical properties, CNT has been added to traditional materials, such as cement-based materials and polymers, for enhancement of their properties.

During the service life of concrete structures, durability is an important issue that must be considered. A number of severe environmental factors can deteriorate the mechanical performances of structural materials. For example, the hot dry environment is often considered to damage the durability of cement-based materials due to insufficient hydration, as well as the freeze-thaw cycling (FT) which can induce a series of internal micro-cracks in cement-based materials. In continental areas such as central Asia and parts of North America concrete could even experience both of these two extreme conditions (i.e., cold weather in winter and hot climate in summer), and therefore designers need information about the performances of the materials when wet and frozen in winter as well as when hot and dry in summer [4]. Drying shrinkage and insufficient hydration are of great concern for concretes in hot and dry climates [4,5]. Besides, additional stress is generated in concretes by the FT 
effect and the materials become easy to crack and get surface scaling, which may speed up the ingress of detrimental ions and the degradation of mechanical properties [6-10]. In these areas, cement-based materials are required to have satisfactory performance in such severe environments.

Based on research, the mechanism for using $\mathrm{CNT}$ as a reinforcing component in cement-based material is based on its bonding, bridging and mesh filling effects [11-13], which redistribute the inner stress and inhibit the propagation of micro-cracks. The influences of CNT on the properties of cement-based materials from the aspect of durability can be divided into two series. On the one hand, some researchers have found that CNT is helpful for improvement of durability. Makar et al. [14] dispersed single-walled CNT (SWCNT) by sonication and observed from the cracks in SEM micrographs that SWCNT acted as bridges and reinforced the matrix; Han et al. [15] found that multi-walled CNT (MWCNT) could decrease the absorption coefficient, water permeability and gas permeability of cement-based materials. On the other hand, CNT was also reported to have detrimental effects on durability. Del et al. [16] detected a slight increase in porosity when CNT was added to cement-based material; the results also showed that the addition of CNT increased the degradation of concrete under carbonation and promoted the ingress of chloride ions; the reason for the higher corrosion level is that higher CNT dosage leads to higher conductivity and therefore a higher galvanic coupling effect from the CNT to the steel reinforcement. In summary, the reasons for getting the two contrary results from different works are complicated, but may include the different dispersion methods and dosages of CNT used in the studies.

During the use of CNT in cement-based materials, dispersion of CNT is an important step and influences the properties obtained. At the moment, dispersions of CNT into water by means of surfactant and sonication [17-20] are commonly used. Konsta-Gdoutos et al. [21] found that surfactant in combination with sonication could effectively disperse CNT in water. During the sonication, bubbles created by waves release high levels of energy and separate individual CNT from bundles. Besides, surfactant can be absorbed to the CNT surface and protects CNT from agglomeration. However, the surfactant applied was also found to act as an air entraining agent and resulted in adverse effects to the mechanical properties [22], while longer sonication pretreatment on the CNT may break its structure [23]. In 2013, Saravanan et al. [24] used a high energy ball milling process to disperse CNT into AA 4032 nanocrystalline matrix and found no structural damage in the CNT. Therefore, in this study, the ball milling dispersion method was used to disperse CNT during the casting of the samples.

Due to lack of a systematic study on the effect of CNT on the mechanical properties of cement-based materials under drying and freeze-thaw cycle conditions, this study is crucial to close the knowledge gap.

\section{Experimental Program}

\subsection{Materials}

The cement used in this study was Type I 42.5R Portland cement manufactured by Guangzhou Xinhe Co., Ltd. (Guangzhou, China). The fine aggregate used was standard sand provided by China ISO Standard Sand Co., Ltd. (Xiamen, China). The carbon nanotube was carboxylated MWCNT offered by Chengdu Institute of Organic Chemistry Research Institute (Chengdu, China). Its morphology and physical properties are shown in Figure 1 and Table 1, respectively. A polycarboxylate based superplasticizer was used to make sure that the cement composite specimens had similar workability.

\subsection{Mix Proportions}

Specimens with four different dosages of MWCNT, viz. $0 \%, 0.1 \%, 0.3 \%, 0.5 \%$ by weight of cement, were used in this study and they were denoted as "Control" and "Q-CNT", respectively, where the "Q-CNT" indicates specimens with CNT. The content of superplasticizer used in each mix was determined on the basis of a slump diameter test, and the value was controlled at $160( \pm 5) \mathrm{mm}$ in this study. Detailed mix proportions are listed in Table 2. 


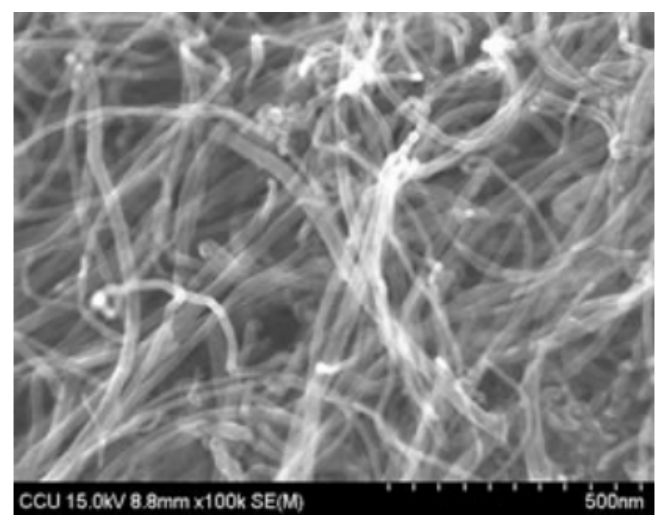

Figure 1. Scanning electon microscopy (SEM) image of multi-walled CNT (MWCNT).

Table 1. Properties of the multi-walled CNT (MWCNT) used in this study.

\begin{tabular}{cccccc}
\hline Type & Diameter & Length & Purity & Specific Surface Area & -COOH \\
\hline MWCNT & $10-20 \mathrm{~nm}$ & $10-30 \mu \mathrm{m}$ & $>95 \%$ & $>120 \mathrm{~m}^{2} \cdot \mathrm{g}^{-1}$ & $2 \mathrm{wt} \%$ \\
\hline
\end{tabular}

Table 2. Mix proportions (unit: g).

\begin{tabular}{cccccc}
\hline Specimen & Cement & Sand & Water & MWCNT & Superplasticizer \\
\hline Control & 100 & 100 & 45 & 0 & 0.2 \\
Q1-CNT & 100 & 100 & 45 & 0.1 & 0.3 \\
Q3-CNT & 100 & 100 & 45 & 0.3 & 0.4 \\
Q5-CNT & 100 & 100 & 45 & 0.5 & 0.6 \\
\hline
\end{tabular}

\subsection{Manufacture and Curing of Specimens}

In the experiment, manufacturing and curing of samples followed the procedures listed below:

1. One $\mathrm{g}$ of MWCNT was mixed with $20 \mathrm{~g}$ of cement into an agate jar for the ball milling process, and the ball/mixture ratio (by mass) was 40:1;

2. The mixtures of cement and MWCNT were milled for $0.5 \mathrm{~h}$ with a QM-QX2 ball mill, manufactured by Nanjing Nanda Co., Ltd. (Nanjing, China), at a speed of $200 \mathrm{rpm}$ for a homogeneous dry MWCNT-cement mixture;

3. Cement, sand, superplasticizer, and the pre-milled MWCNT-cement mixture were added into a NJ-160A cement mixer (manufactured by Wuxi Jianyi Experimental Instrument Co., Ltd., Wuxi, China), together with designated amount of water. The mixer was switched on at a quick speed for $3 \mathrm{~min}$ for fresh CNT/cement composite;

4. Fresh specimens were cast with steel molds into two different dimensions, which were $280 \mathrm{~mm} \times 25 \mathrm{~mm} \times 25 \mathrm{~mm}$ and $160 \mathrm{~mm} \times 40 \mathrm{~mm} \times 40 \mathrm{~mm}$. The previous samples were cast for testing the drying shrinkage; the latter ones were cast to study the mechanical properties and analyses of the microstructure;

5. The specimens were demolded after $24 \mathrm{~h}$ from the cast and cured by two different regimes. The $280 \mathrm{~mm} \times 25 \mathrm{~mm} \times 25 \mathrm{~mm}$ samples designed for testing the drying properties were exposed to a drying condition with $20{ }^{\circ} \mathrm{C}$ and relative humidity (RH) of $50 \%$; the $160 \mathrm{~mm} \times 40 \mathrm{~mm} \times 40 \mathrm{~mm}$ samples were exposed to a standard curing condition with $20^{\circ} \mathrm{C}$ and $\mathrm{RH}$ of $95 \%$ until test.

\subsection{Mechanical Properties Test}

To study the effect of CNT on the mechanical properties of cement-based materials, the flexural strength and compressive strength of samples cured in a standard environment for 28 days were 
determined. The flexural and compressive tests were conducted according to ASTM C348 and ASTM C349, respectively.

\subsection{Morphology and Pore Characteristics Study}

Morphology and analyses of pore characteristics were carried out on samples cured in the standard condition for 28 days. The morphology of the composite was observed by SU-70 scanning electron microscopy (SEM) and the pore characteristics were analyzed by mercury intrusion porosimetry (MIP) (AutoPore IV 9500, manufactured by Micromeritics, Shanghai, China).

\subsection{Properties under Drying Conditions}

The drying shrinkage and water loss were explored on the $280 \mathrm{~mm} \times 25 \mathrm{~mm} \times 25 \mathrm{~mm}$ and $160 \mathrm{~mm} \times 40 \mathrm{~mm} \times 40 \mathrm{~mm}$ samples, respectively. The initial length $\left(L_{0}\right.$, in $\left.\mathrm{mm}\right)$ and mass of specimen $\left(W_{0}\right.$, in $\left.\mathrm{g}\right)$ were measured after demolding of the samples after the one day of curing in molds. Subsequently, samples were placed in the drying room with a controlled temperature of $20^{\circ} \mathrm{C}$ and $\mathrm{RH}$ of $50 \%$ for drying curing. During the drying stage, the length $\left(L_{n}\right.$, in $\left.\mathrm{mm}\right)$ and mass $\left(W_{n}\right.$, in g) of the specimens were tested every $24 \mathrm{~h}$ for 6 days. The lengths of the specimens were measured by a length gauge with an accuracy of $0.002 \mathrm{~mm}$ and the drying shrinkage $\varepsilon$ was calculated following Equation (1). For the mass change, the water loss rate, $S$, was determined following Equation (2).

$$
\begin{gathered}
\varepsilon=\frac{L_{0}-L_{n}}{L_{0}} \times 100 \% \\
S=\frac{W_{0}-W_{n}}{W_{0}} \times 100 \%
\end{gathered}
$$

The flexural strength and the compressive strength of specimens with dimension of $160 \mathrm{~mm} \times 40 \mathrm{~mm} \times 40 \mathrm{~mm}$ at 3,7 , and 28 days of the drying stage were also tested in this study, following the ASTM C348 and C349 standard.

\subsection{Freeze-Thaw Cycling}

Before exposing to FT regimes, the $160 \mathrm{~mm} \times 40 \mathrm{~mm} \times 40 \mathrm{~mm}$ specimens that were used for studying the anti-frost effect, experienced a 24-day standard curing and another 4-day immersion in water after demolding.

The FT regime was consistent with placement of specimens into a freezer for $16 \mathrm{~h}$ at a temperature of $-20^{\circ} \mathrm{C}$ and a subsequent immersion in water for $8 \mathrm{~h}$ at a temperature of $20^{\circ} \mathrm{C}$. The compressive strength of the specimens was tested after 30, 60, and 90 FT cycles, which was prescribed in GB/T50082 2009 as a key parameter for indicating the degree of degradation of cement-based materials under FT effect. The loss rate of compressive strength, $\Delta f_{c}$, was calculated based on Equation (3).

$$
\Delta f_{c}=\frac{f_{c 0}-f_{c n}}{f_{c 0}} \times 100 \%
$$

where $f_{c n}$ is the compressive strength (MPa) of specimen after $n$ FT cycles; $f_{c 0}$ is the compressive strength (MPa) of specimens constantly placed in the standard curing environment and tested together with the FT samples.

For all the mechanical tests, shrinkage and anti-frost tests carried out in this study, three replicates were measured for each mix and their average values were used to indicate the results. For the MIP measurement, two replicates were measured for each mix.

\section{Experimental Analysis}

\subsection{Mechanical Strengths}

Figure 2 shows the flexural and compressive strengths of specimens after 28-day standard curing. 


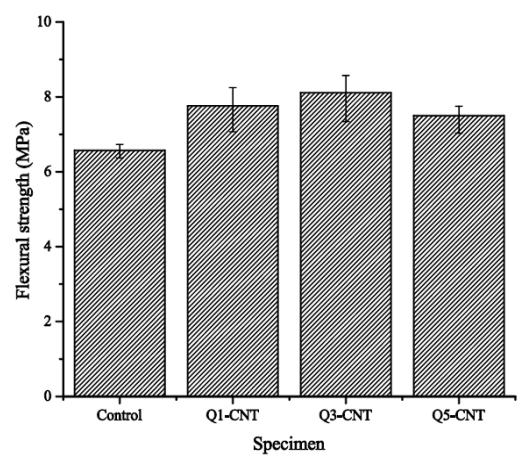

(a)

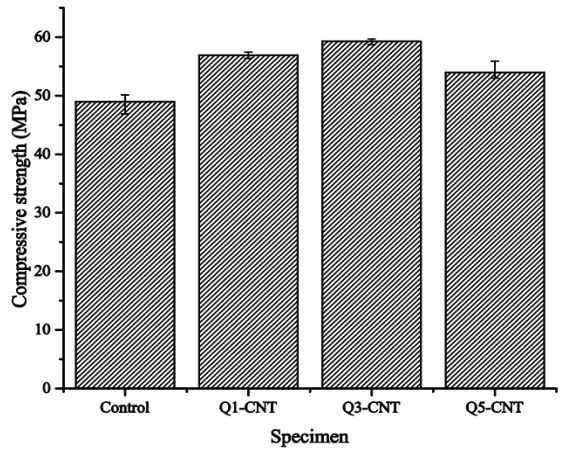

(b)

Figure 2. Flexural and compressive strengths of samples in standard curing. (a) Flexural strength; (b) Compressive strength.

As seen from the results, addition of the MWCNT led to an increase in both the flexural and compressive strengths. The largest improvements were observed in the Q3-CNT specimens, which were a $23.4 \%$ higher in the flexural strength and $21.1 \%$ higher in compressive strength. Further increase in the MWCNT content to a dosage of $0.5 \%$ led to a noticeable decrease in both the flexural strength and compressive strength in this study.

The improvements from CNT on the mechanical strengths of specimens have also been observed by many researchers and its mechanisms can be concluded as:

1. The effective network formed by MWCNT embedding firmly in the hydration products plays significant roles of bonding and bridging effects for the matrix [11]. This enhancement can provide higher stress when the crack goes straight toward the MWCNT reinforced zone area and prevent propagation of cracks at a high speed [25].

2. Carboxylic acid groups on the surface of MWCNT react with the calcium silicate hydrate and result in a strong embedding strength between the MWCNT and matrix [19].

By comparing the results obtained from this study with those published in the literature, as summarized in Table 3, it is noteworthy that in most cases CNT was dispersed by means of ultrasonication and surfactant. The extent of improvement in mechanical properties of cement composite varies from different studies, which can be attributed to the dispersion method, types and content of CNT used. In this study, CNT dispersed by the ball-milling dispersion method provided comparable enhancement in mechanical properties as good as with those dispersed by the ultrasonication and surfactant method. Therefore, results obtained from this study proved that the ball-milling method is an effective alternative for CNT dispersion in the cement matrix. 
Table 3. Summary of different techniques used for CNT dispersion in the cement matrix and resulting improvement in mechanical properties.

\begin{tabular}{cccc}
\hline Type and Content & Dispersion Technique & Improvement in Mechanical Properties & Researchers and Reference \\
\hline $0.05 \%$ MWCNT & $\begin{array}{c}\text { Ultrasonication and } \\
\text { superplasticizer }\end{array}$ & $\begin{array}{c}\text { Compressive and flexural strength } \\
\text { improved by 7\% and 6\% }\end{array}$ & Del et al. [16] \\
\hline $0.5 \%$ MWCNT & $\begin{array}{c}\text { Functionalization with } \\
\mathrm{HNO}_{3} / \mathrm{H}_{2} \mathrm{SO}_{4} \text { mixture and } \\
\text { direct mixing with cement }\end{array}$ & $\begin{array}{c}\text { Compressive and flexural strength } \\
\text { improved by 19\% and 25\% }\end{array}$ & Li et al. [19] \\
\hline $0.15 \%$ MWCNT & Direct mixing with cement & No improvement in compressive strength & Kim et al. [25] \\
\hline $0.1 \%$ SWCNT & Ultrasonication and surfactant & $\begin{array}{c}\text { Compressive and flexural strength } \\
\text { improved by 19\% and 7\% }\end{array}$ & Parveen et al. [26] \\
\hline $1 \%$ MWCNT & Direct mixing with cement & $\begin{array}{c}\text { Compressive strength improved by 10\% } \\
\text { Compressive and flexural strength } \\
\text { improved by 23.4\% and 21.1\% }\end{array}$ & Torkittikul et al. [27] \\
\hline $0.3 \%$ MWCNT & Ball-milling & et al. (Present work) \\
\hline
\end{tabular}

\subsection{Microstructure of Specimens}

\subsubsection{Morphology of the CNT/Cement Composite}

SEM micrographs of the hydrated CNT/cement composite structure after 28-day curing are presented in Figure 3. As shown in Figure 3a-c, with the increase in content, MWCNT agglomerated much more obviously; this could be attributed to the Van der Waals' force between MWCNT. The agglomeration of MWCNT was the weak area of the matrix and could be the main reason for the reduction in mechanical properties (but still higher than that of control specimen), as shown in Figure 2. Figure 3d shows that MWCNT presented a net-like morphology in the pores of the cement hydration product, which was considered to be the most idealistic structure for MWCNT [25]. Generally, higher content of MWCNT requires more energy for dispersion during the milling process. Therefore, the ball milling method used in this study needs further improvement based on the dosage of MWCNT added. Figure 3e proves that parts of the MWCNT added in the Q3-CNT sample were well dispersed and the individual MWCNT was firmly wedged into the cement hydration products [28]. In the sub-area of Figure 3e with a magnification of $90 \mathrm{k}$, an individual CNT with a diameter of $32.29 \mathrm{~nm}$ was shown and interconnected hydration products. Besides, according to the activation theory [29], the ball milling process used, also charged the MWCNT surface and activated cement particles, which was helpful for interactive reaction between MWCNT and the cement hydration products.

\subsubsection{Pore Characteristics of the CNT/Cement Composite}

With the initial study, it was found that the Q3-CNT specimen had the highest 28-day compressive strength. This mix was selected as the example for discussing the influence of MWCNT on pore characteristics and properties of the cement composite under drying regimes and FT cycles in the following discussions.

Table 4 and Figure 4 present pore characteristics for the Control and Q3-CNT specimens. As seen in Table 4, a slight increase in porosity was detected in the Q3-CNT at the 28th day compared to the control. The addition of MWCNT led to a decrease in pores with diameter smaller than $100 \mathrm{~nm}$ by $5.5 \%$, pores with diameter bigger than $200 \mathrm{~nm}$ a decrease by 33.1\%, and those in the range of 100-200 nm increased by $55.1 \%$. It indicates that MWCNT addition can significantly reduce the volume of pores with a diameter of greater than $200 \mathrm{~nm}$. Pores of this size are regarded as having a detrimental effect on the mechanical properties and durability of cement-based materials [30]. The increase in pore volume can be ascribed to filling of entangled MWCNT in larger voids, shown in Figure 3d, and dividing the pores into smaller sizes and forming a meshed cement mortar structure. 


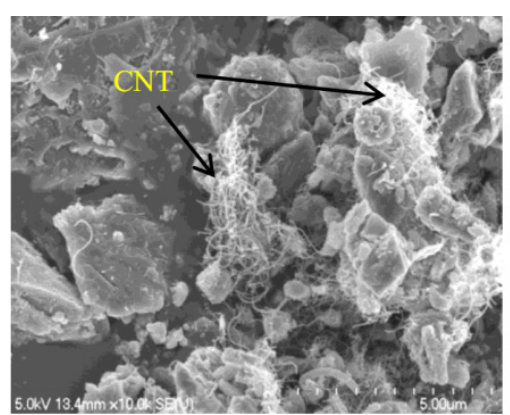

(a)

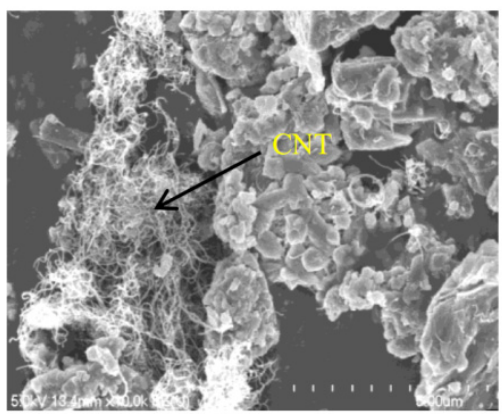

(c)

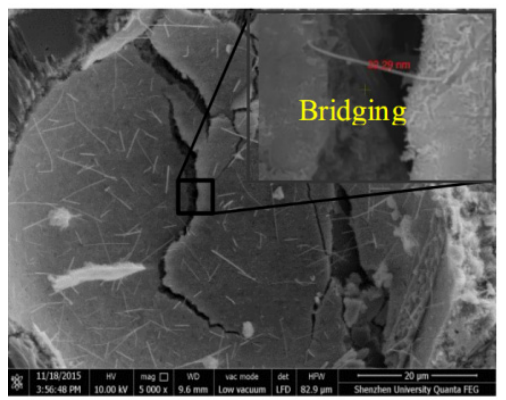

(e)

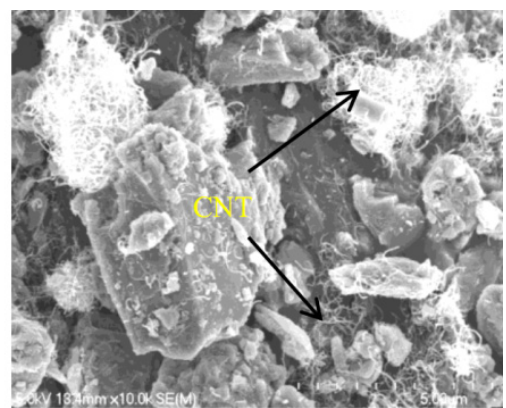

(b)

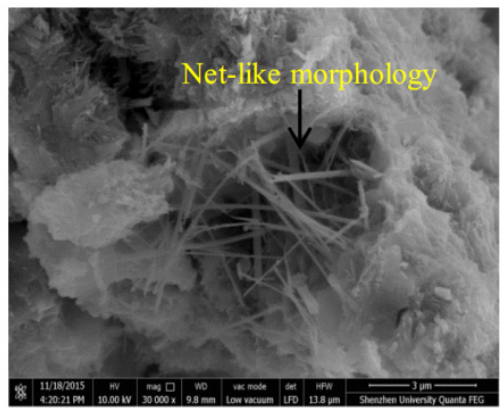

(d)

Figure 3. SEM images of the CNT/cement composite at an age of 28 days. (a) Q1-CNT $\times 10 k$; (b) Q3-CNT $\times 10 \mathrm{k}$; (c) Q5-CNT $\times 10 \mathrm{k}$; (d) Q3-CNT $\times 30 \mathrm{k}$; (e) Q3-CNT $\times 5 \mathrm{k}$.

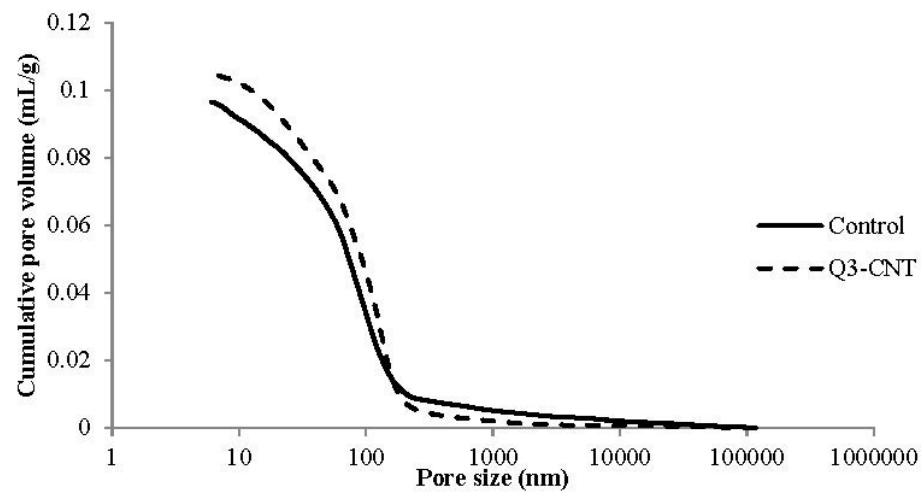

Figure 4. Pore size distribution curves of the Control and Q3-CNT specimens. 
Table 4. Porosity and pore size distribution.

\begin{tabular}{cccccc}
\hline \multirow{2}{*}{ Specimen } & \multirow{2}{*}{ Porosity (\%) } & \multicolumn{4}{c}{ Pore Size Distribution $\mathbf{( m L / g )}$} \\
\cline { 3 - 6 } & & $\mathbf{< 5 0} \mathbf{~ n m}$ & $\mathbf{5 0 ~ 1 0 0 ~} \mathbf{~ m ~}$ & $\mathbf{1 0 0 ~ 2 0 0 ~} \mathbf{~ m}$ & $>\mathbf{2 0 0} \mathbf{~ n m}$ \\
\hline Control & 18.59 & 0.0316 & 0.0284 & 0.0274 & 0.0092 \\
Q3-CNT & 19.62 & 0.0317 & 0.0250 & 0.0425 & 0.0061 \\
\hline
\end{tabular}

\subsection{Drying Properties}

\subsubsection{Water Loss of Specimen under Drying}

Results of water loss for the control and Q3-CNT specimens are shown in Figure 5. The Q3-CNT specimen had a smaller water loss and a lower rate, compared with the control specimen. For both of the two samples, the water loss was comparatively at a high speed in the initial two days, and subsequently became stabilized. The addition of $0.3 \%$ MWCNT led to a reduction of lower water evaporation by $13.3 \%$ for the first six days of drying, indicating that there were less open pores in the Q3-CNT specimen.

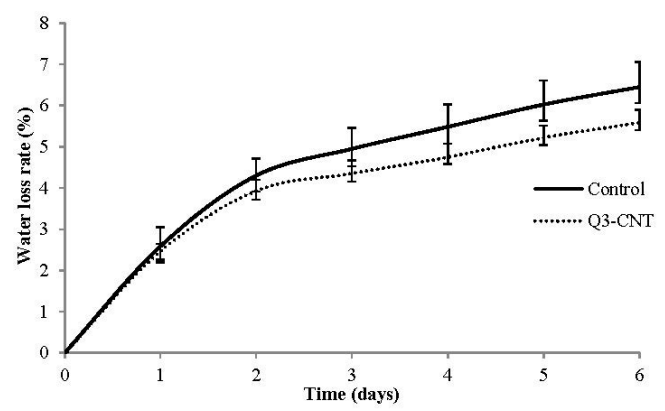

Figure 5. Average value of water loss rate.

\subsubsection{Drying Shrinkage}

Figure 6 shows the development of daily and cumulative drying shrinkage of the control and Q3-CNT specimens in the studied drying stage. It can be seen that, the shrinkage of the Q3-CNT was at a much lower rate in comparison to the control specimen. Also, the drying shrinkage of both the two specimens was at a relatively high speed in the first two days, which gradually decreased in the succeeding four days. This development of drying shrinkage is consistent with the results of water lose rate as presented in Figure 5. At the end of the drying stage studied, the shrinkages of the Control and Q3-CNT specimens were $0.112 \%$ and $0.085 \%$, respectively. Addition of $0.3 \%$ MWCNT led to an apparent reduction of $31.9 \%$ in the drying shrinkage.

\subsubsection{Development of Flexural Strength and Compressive Strength under the Drying Condition}

Figure 7 shows the flexural and compressive strengths of the control and Q3-CNT specimens placed under drying and standard conditions for 3, 7, and 28 days. During the drying, the flexural and compressive strengths of the Q3-CNT were higher than those of the control. The compressive strength of both the control and Q3-CNT obviously increased after the first 7 days under the drying condition, and a marginal improvement was detected at the 28th day. After the 28-day drying, the addition of MWCNT by a dosage of $0.3 \%$ led to an increase in flexural and compressive strengths by $24 \%$ and $12.4 \%$ respectively. In the development of flexural strength, there was a noticeable decrease from 3 days to 7 days, as seen in Figure 7a. Similar findings have also been reported by Al-Rub and Tyson et al. [17,31]. Based on the theory of Tyson et al. [31], the curing process would delay the formation of high stiffness C-S-H at the early days and hence delay the bonding mechanism between $\mathrm{CNT}$ and the cement matrix, which might explain the decrease in the flexural strength at the 7th day. 


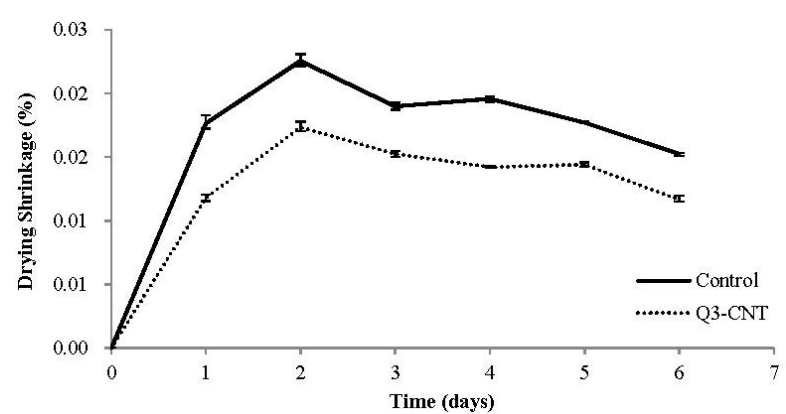

(a)

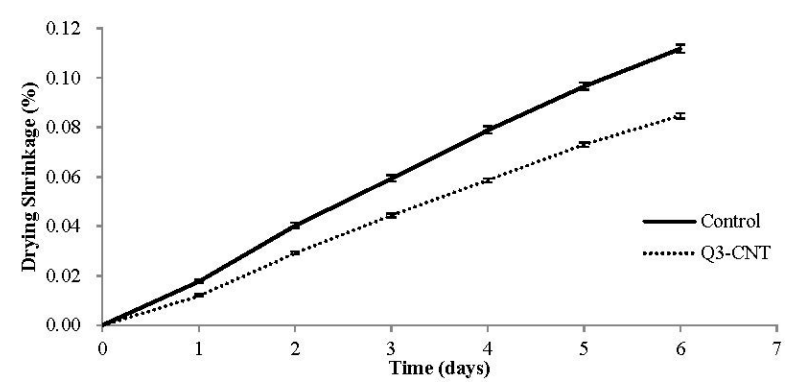

(b)

Figure 6. Development of drying shrinkage for the control and Q3-CNT specimens. (a) Average value of daily drying shrinkage; (b) Average value of cumulative drying shrinkage.

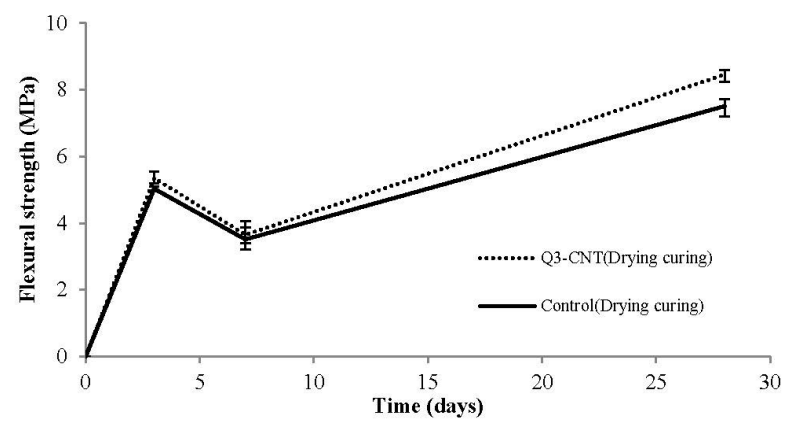

(a)

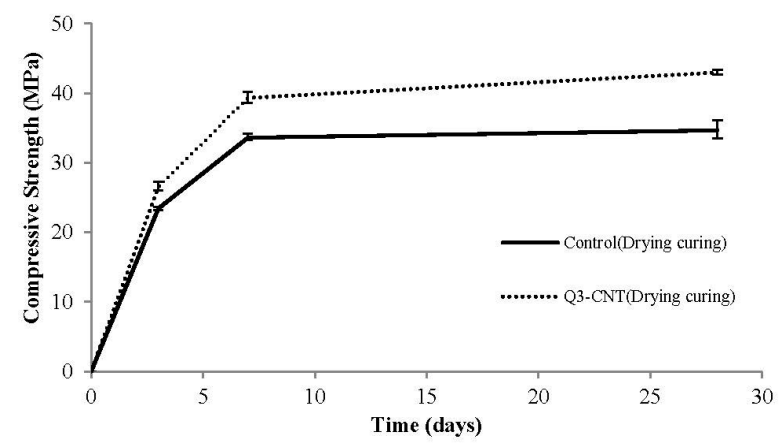

(b)

Figure 7. The flexural and compressive strengths of the control and Q3-CNT specimens under drying conditions (a) Average value of flexural strength; (b) Average value of compressive strength.

The mechanism of CNT/cement composites for the improvement in the drying process could be explained as follows:

1. The reasons for lower shrinkage could be attributed to less moisture migration and improved pore structures. For one reason, addition of MWCNT caused a reduction in the evaporation 
paths for water and the rate of water loss, preventing moisture migration to the outer surface and leading finally to lower drying shrinkage [32]. For another, MWCNT achieved the enhancement effect by increasing the amount of C-S-H gel of high hardness and improving pore structures [33].

2. The reasons for higher mechanical strength could be attributed to the improved pore structures and higher anti-cracking resistance. Both micro-cracks caused by a tension state on the surface [34] and insufficient hydration are detrimental to dried mortar and theoretically lead to reduction in compressive strength of the specimens. For one reason, during evaporation, water transports from the core area to the surface through pores of different dimensions, in which capillary pores act as a moving path and macro pores act as reservoirs for water evaporation. In the Q3-CNT specimen, there are less large pores on the surface zone and more water remains in the specimen [35], leading to further cement hydration. For another, the lower shrinkage has a significant effect on the mechanical behavior, as the development of micro-cracks due to volumetric changes is reduced. The bridging effect of MWCNT shown in SEM images will also lead to higher flexural and compressive strengths in the drying conditions.

\subsection{Freeze-Thaw Cycling Test}

In Figure 8, the histogram shows the compressive strength of specimens, and the line shows the degradation of the compressive strength under the effect of FT cycling. During the studied duration, the decrease in compressive strength for the Q3-CNT was lower than that of the control, which implies a better resistance of the $\mathrm{CNT} /$ cement composite against the FT effect.

$$
\ln \left(\frac{T}{T_{0}}\right)=-\frac{2 \times \Delta G \times v_{w}}{\Delta h \times r}
$$

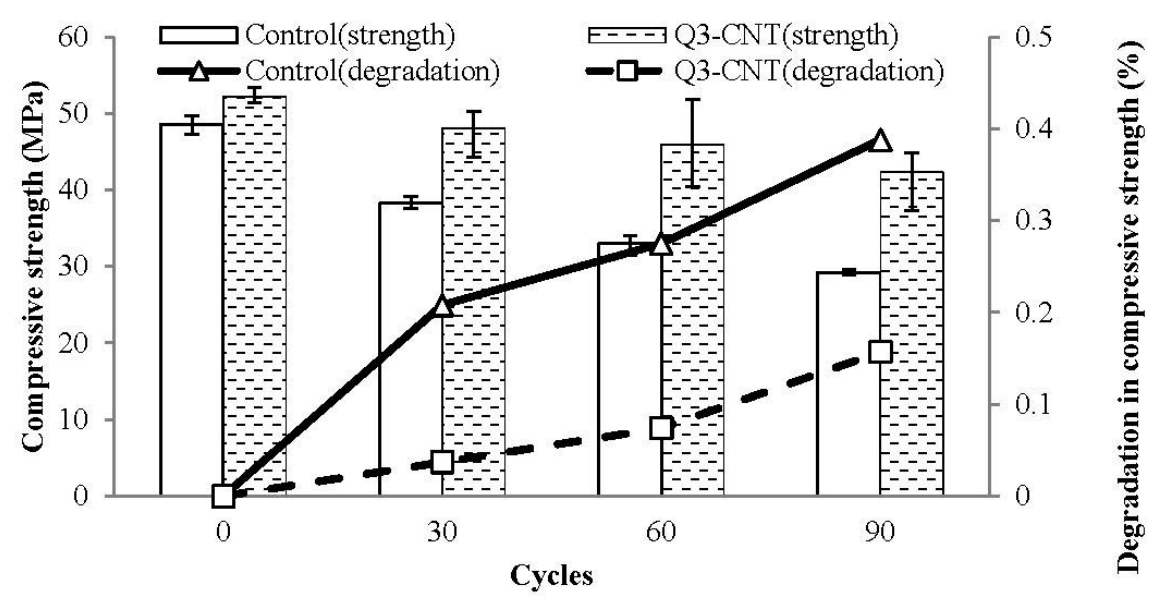

Figure 8. Degradation in compressive strength of the control and Q3-CNT specimens under freeze-thaw (FT) cycles.

Equation (4) is a derived Gibbs Thomson equation presented by Penttala [36]. In this equation, $T\left({ }^{\circ} \mathrm{K}\right)$ is the temperature of pore liquid; $T_{0}\left({ }^{\circ} \mathrm{K}\right)$ is the freezing temperature of the bulk liquid at a pressure of 1 bar; $\Delta G$ is the interfacial energy change between matrix and frozen liquid and between matrix and liquid during freezing; $v_{W}$ is the specific volume of water; $\Delta h$ is the latent heat of fusion; and $r$ is the pore radius. This equation can be further derived into the following Equation (5).

$$
T_{0}=T \times e^{\frac{2 \times \Delta G \times v_{w}}{\Delta h \times r}}
$$

From Equation (5), it can be concluded that the pore solution in bigger pores (a bigger " $\mathrm{r}$ " value) has a lower freezing temperature. Therefore, it can be deduced that during the decrease in temperature from modest room temperature to a frozen state, the solution in bigger pores freezes first. As a consequence, the unfrozen solution in smaller pores will be forced into the bigger pores via their 
connection channels, leading to a further increase in the diameter of ice crystals, which causes a further expansion [36]. This explains the better FT resistance of the MWCNT samples that have fewer bigger pores, as proved previously.

Besides, the better FT resistance of the MWCNT samples can also be attributed to the interlocking and bridging effects of the MWCNT in the hydrated cement paste.

Furthermore, the movement of gel water from smaller pores to bigger ones under the FT cycles will cause drying shrinkage of the gel structure [36]. This might be relative to the drying shrinkage tested during the drying curing of this study. The lower shrinkage has a significant effect on the FT resistance, as the development of micro-cracks due to volumetric changes is reduced. Therefore, fewer micro-cracks would prevent the penetration of the unfrozen solution and lead to smaller generation of osmotic pressure in the pore system.

\section{Conclusions}

This paper presents the results of investigation on the properties of cement mortar incorporated with MWCNT. Cement mortar samples with four different concentrations of MWCNT (0 wt \%, $0.1 \mathrm{wt} \%, 0.3 \mathrm{wt} \%$, and $0.5 \mathrm{wt} \%$ ) were designed for this study. The morphology of the MWCNT in the cement matrix and its effect on the flexural strength, compressive strength, porosity, drying shrinkage, and FT resistance properties were investigated. The following conclusions were drawn from the study.

i. Carbon nanotube dispersed by the ball-milling method in cement matrix provided enhanced mechanical properties. At a dosage of $0.3 \%$ of cement, the carbon nanotube/cement composite has the highest mechanical strength in this study.

ii. With addition of carbon nanotube to the cement mortar, pores with a diameter of bigger than 200 $\mathrm{nm}$ are likely to be refined to $50-100 \mathrm{~nm}$; the disconnection of pores was also improved.

iii. Samples incorporated with carbon nanotube have a better performances than the pure cement mortar under drying and the freeze-thaw conditions. This is attributed to pores refinement, drying shrinkage reinforcement, and the bridging effect of the carbon nanotube.

Acknowledgments: The authors would like to gratefully acknowledge the Shenzhen Strategic Emerging Industry Development Special Fund (Project number: JCYJ20150625102603853), Nature and Science Foundation of China (Project number: 51408366) and the Ministry of Science and Technology for the 973-project (Grant number: 2011CB013604) for financial support on this study.

Author Contributions: Wei-Wen Li sketched the initial idea of this study, contributed to the experimental design and handled the progress of the entire project. Wei-Ming Ji was the main operator for this study, carried out data analyses and drafted this paper. Yao-Cheng Wang contributed to the revision on this paper, including further data analyses, logic of discussion during writing and basic grammar revision. Yi Liu and Ruo-Xu Shen carried out the initial trial experiments and parts of the results. Feng Xing offered suggestions and detailed methods used for this study and commented on data analyses.

Conflicts of Interest: The authors declare no conflict of interest.

\section{References}

1. Salvetat, J.P.; Bonard, J.M.; Thomson, N.H.; Kulik, A.J.; Forro, L.; Benoit, W.; Zuppiroli, L. Mechanical properties of carbon nanotubes. Appl. Phys. A 1999, 69, 255-260. [CrossRef]

2. Belytschko, T.; Xiao, S.P.; Schatz, G.C.; Ruoff, R.S. Atomistic simulations of nanotube fracture. Phy. Rev. B 2002, 65, 235430-235438. [CrossRef]

3. Kaushik, B.K.; Goel, S.; Rauthan, G. Future VLSI interconnects: Optical fiber or carbon nanotube-A review. Microelectron. Int. 2007, 24, 53-63. [CrossRef]

4. Badr, A. Influence of severe environment on the performance of concrete containing construction and industrial waste. Available online: http://conmat15.ic-impacts.com/wp-content/uploads/2015/ 03/Paper116_Badr.pdf (accessed on 1 December 2015).

5. Atiş, C.D.; Özcan, F.; Kılıc, A.; Karahan, O.; Bilim, C.; Severcan, M.H. Influence of dry and wet curing conditions on compressive strength of silica fume concrete. Build. Environ. 2005, 40, 1678-1683. [CrossRef] 
6. Carde, C.; Francois, R. Modelling the loss of strength and porosity increase due to the leaching of cement pastes. Cem. Concr. Compos. 1999, 21, 181-188. [CrossRef]

7. Mainguy, M.; Tognazzi, C.; Torrenti, J.M.; Adenot, F. Modelling of leaching in pure cement paste and mortar. Cem. Concr. Res. 2000, 30, 83-90. [CrossRef]

8. Moranville, M.; Kamali, S.; Guillon, E. Physicochemical equilibria of cement-based materials in aggressive environments-Experiment and modeling. Cem. Concr. Res. 2004, 34, 1569-1578. [CrossRef]

9. Rozière, E.; Loukili, A.; el Hachem, R.; Grondin, F. Durability of concrete exposed to leaching and external sulphate attacks. Cem. Concr. Res. 2009, 39, 1188-1198. [CrossRef]

10. Medina, C.; de Rojas, M.I.S.; Frías, M. Freeze-thaw durability of recycled concrete containing ceramic aggregate. J. Clean. Prod. 2013, 40,151-160. [CrossRef]

11. Xu, S.; Liu, J.; Li, Q. Mechanical properties and microstructure of multi-walled carbon nanotube-reinforced cement paste. Constr. Build. Mater. 2015, 76, 16-23. [CrossRef]

12. Ning, J.; Zhang, J.; Pan, Y.; Guo, J. Fabrication and mechanical properties of $\mathrm{SiO}_{2}$ matrix composites reinforced by carbon nanotube. Mater. Sci. Eng. A 2003, 357, 392-396. [CrossRef]

13. Saffar, K.P.; Najafi, A.R.; Moeinzadeh, M.H.; Sudak, L.J. A Finite Element Study of Crack Behavior for Carbon Nanotube Reinforced Bone Cement. World J. Mech. 2013, 3, 13-21. [CrossRef]

14. Maker, J.M.; Margeson, J.C.; Luh, J. Carbon nanotube/cement composites early results and potential applications. In Proceedings of the 3rd International Conference on Construction Materials: Performance, Innovations and Structural Implications, Vancouver, BC, Canada, 22-24 August 2005; pp. 1-10.

15. Han, B.; Yang, Z.; Shi, X.; Yu, X. Transport properties of carbon-nanotube/cement composites. J. Mater. Eng. Perform. 2013, 22, 184-189. [CrossRef]

16. Del, C.C.M.; Galao, O.; Baeza, F.J.; Zornoza, E.; Garcés, P. Mechanical properties and durability of CNT cement composites. Materials 2014, 7, 1640-1651.

17. Al-Rub, R.K.A.; Ashour, A.I.; Tyson, B.M. On the aspect ratio effect of multi-walled carbon nanotube reinforcements on the mechanical properties of cement-based nanocomposites. Constr. Build. Mater. 2012, 35, 647-655. [CrossRef]

18. Collins, F.; Lambert, J.; Duan, W.H. The influences of admixtures on the dispersion, workability, and strength of carbon nanotube-OPC paste mixtures. Cem. Concr. Compos. 2012, 34, 201-207. [CrossRef]

19. Li, G.Y.; Wang, P.M.; Zhao, X. Mechanical behavior and microstructure of cement composites incorporating surface-treated multi-walled carbon nanotubes. Carbon 2005, 43, 1239-1245. [CrossRef]

20. Wang, B.; Han, Y.; Liu, S. Effect of highly dispersed carbon nanotubes on the flexural toughness of cement-based composites. Constr. Build. Mater. 2013, 46, 8-12. [CrossRef]

21. Konsta-Gdoutos, M.S.; Metaxa, Z.S.; Shah, S.P. Highly dispersed carbon nanotube reinforced cement based materials. Cem. Concr. Res. 2010, 40, 1052-1059. [CrossRef]

22. Kim, H.K.; Nam, I.W.; Lee, H.K. Enhanced effect of carbon nanotube on mechanical and electrical properties of cement composites by incorporation of silica fume. Compos. Struct. 2014, 107, 60-69. [CrossRef]

23. Rossell, M.D.; Kuebel, C.; Ilari, G.; Rechberger, F.; Heiligtag, F.J.; Niederberger, M.; Erni, R. Impact of sonication pretreatment on carbon nanotubes: A transmission electron microscopy study. Carbon 2013, 61, 404-411. [CrossRef]

24. Saravanan, S.; Sivaprasad, K.; Kumaresh, B.S.P. Dispersion and thermal analysis of Carbon nanotube reinforced AA 4032 Alloy produced by high energy ball milling. Exp. Tech. 2013, 37, 14-18. [CrossRef]

25. Sobolkina, A.; Mechtcherine, V.; Khavrus, V.; Maier, D.; Mende, M.; Ritschel, M.; Leonhardt, A. Dispersion of carbon nanotubes and its influence on the mechanical properties of the cement matrix. Cem. Concr. Compos. 2012, 34, 1104-1113. [CrossRef]

26. Parveen, S.; Rana, S.; Fangueiro, R.; Paiva, M.C. Microstructure and mechanical properties of carbon nanotube reinforced cement-based composites developed using a novel dispersion technique. Cem. Concr. Res. 2015, 73, 215-227. [CrossRef]

27. Torkittikul, P.; Chaipanich, A. Bioactivity and mechanical properties of White Portland cement paste with carbon nanotubes. In Proceedings of the 3rd International Nanoelectronics Conference (INEC), Hong Kong, China, 3-9 January 2010; pp. 838-839.

28. Liu, Z.Y.; Xu, S.J.; Xiao, B.L.; Xue, P.; Wang, W.G.; Ma, Z.Y. Effect of ball-milling time on mechanical properties of carbon nanotubes reinforced aluminum matrix composites. Compos. A Appl. Sci. Manuf. 2012, 43, 2161-2168. [CrossRef] 
29. Pandurangappa, M.; Raghu, G.K. Chemically Modified Carbon Nanotubes: Derivatization and Their Applications; INTECH Open Access Publisher: Bangalore, India, 2012; pp. 499-526.

30. Wu, Z.W.; Lian, H.Z. High Performance Concrete; China Railway Publishing House: Beijing, China, 1999.

31. Tyson, B.M.; Abu Al-Rub, R.K.; Yazdanbakhsh, A.; Grasley, Z. Carbon nanotubes and carbon nanofibers for enhancing the mechanical properties of nanocomposite cement-based materials. J. Mater. Civ. Eng. 2011, 23, 1028-1035. [CrossRef]

32. Numao, T.; Mihashi, H. Moisture migration and shrinkage of hardened cement paste at elevated temperatures. In Proceedings of the Transactions of the 11th International Conference on Structural Mechanics in Reactor Technology, Tokyo, Japan, 18-23 August 1991.

33. Khater, H.M.; Gawwad, H.A.A. Characterization of alkali activated geopolymer mortar doped with MWCNT. Adv. Mater. Res. 2015, 4, 45-61. [CrossRef]

34. Wang, Z.W.; Zhang, H.Z. Expansive Concrete; China Railway Publishing House: Beijing, China, 1990.

35. Wilk, D.; Bratasz, Ł.; Kozłowski, R. Shrinkage cracking in Roman cement pastes and mortars. Cem. Concr. Res. 2013, 53, 168-175. [CrossRef]

36. Penttala, V. Freezing-induced strains and pressures in wet porous materials and especially in concrete mortars. Adv. Cem. Based Mater. 1998, 7, 8-19. [CrossRef]

(C) 2015 by the authors; licensee MDPI, Basel, Switzerland. This article is an open access article distributed under the terms and conditions of the Creative Commons by Attribution (CC-BY) license (http:/ / creativecommons.org/licenses/by/4.0/). 